\title{
A systematic review of carbohydrate-based microneedles: current status and future prospects
}

\author{
Rupali S. Bhadale ${ }^{1} \cdot$ Vaishali Y. Londhe $\mathbb{D}^{1}$ \\ Received: 18 November 2020 / Accepted: 7 July 2021 / Published online: 31 July 2021 \\ (c) The Author(s) 2021
}

\begin{abstract}
Microneedles (MNs) are minimally invasive tridimensional biomedical devices that bypass the skin barrier resulting in systemic and localized pharmacological effects. Historically, biomaterials such as carbohydrates, due to their physicochemical properties, have been used widely to fabricate MNs. Owing to their broad spectrum of functional groups, carbohydrates permit designing and engineering with tunable properties and functionalities. This has led the carbohydratebased microarrays possessing the great potential to take a futuristic step in detecting, drug delivery, and retorting to biologicals. In this review, the crucial and extensive summary of carbohydrates such as hyaluronic acid, chitin, chitosan, chondroitin sulfate, cellulose, and starch has been discussed systematically, using PRISMA guidelines. It also discusses different approaches for drug delivery and the mechanical properties of biomaterial-based MNs, till date, progress has been achieved in clinical translation of carbohydrate-based MNs, and regulatory requirements for their commercialization. In conclusion, it describes a brief perspective on the future prospects of carbohydrate-based MNs referred to as the new class of topical drug delivery systems.
\end{abstract}

\section{Graphical Abstract}

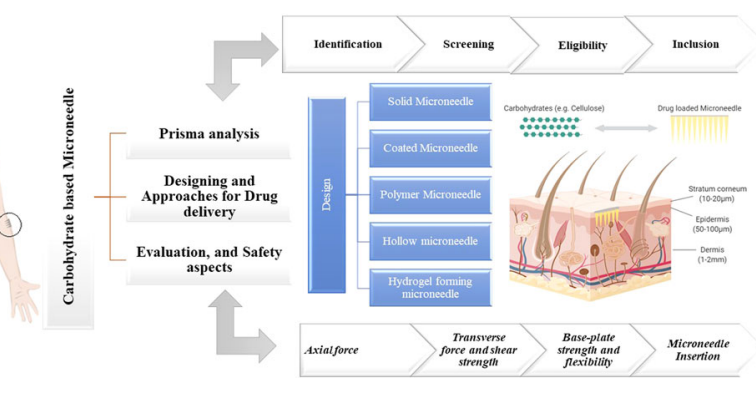

\section{Highlights}

- The transdermal route can be a promising approach for drug delivery.

- Microneedles (MNs), a novel and important transdermal drug delivery system (TDDS), are discussed.

- Prisma guidelines are utilized to review carbohydrate-based MNs for medical applications.

- More innovative applications are predicted owing to their physiological features.

Vaishali Y. Londhe

Vaishali_londhe2000@yahoo.com

1 Shobhaben Pratapbhai Patel School of Pharmacy \& Technology Management, SVKM's NMIMS, Vile Parle [W], Mumbai 400056 Maharashtra, India

\section{Introduction}

Over the last few decades, we have witnessed captivating technology development in drug delivery systems. This technology improvement has enhanced the therapeutic efficiency of biotherapeutics (e.g., vaccines and macromolecules) and hydrophilic drugs [1]. The therapeutic efficiency depends on the administration route, the aim is to overcome the challenges of the conventional drug 
delivery system [2]. The notable drawbacks of the oral and parenteral delivery system are the first-pass metabolism in oral dosage form and poor patient compliance, respectively. This led to the need to develop a delivery system with reduced dosing frequency, self administration, and better patient compliance, economical and ecofriendly $[3,4]$.

Emerging techniques, like the transdermal drug delivery system (TDDS), mainly focus on delivering therapeutic agents through the skin. Universally known, the transdermal route evades the first-pass metabolism, drug-food, and drug-drug interaction, thus enhancing the bioavailability of the therapeutic agents [5, 6]. An ideal candidate for TDDS is a hydrophobic drug molecule with potent action, low molecular weight ( $\mathrm{M} / \mathrm{W} \leq 400$ Dalton), and lower diffusion rate. Though an attractive alternative, TDDS possesses a major hurdle—stratum corneum, i.e., the skin barrier [3, 6].

A three-dimensional, needle-like biomedical device that efficiently delivers the drug through the skin barrier without disturbing and overcoming the conventional method's limitation, microneedles present themselves as a promising development for TDDS, comprising micronsize arrays organized in a small area [7,8]. This device is developed with the aim to overcome the shortcomings of a hypodermic needle and transdermal patch. The first research was published in the late 2000s, and since then, the research activities have grown exponentially, as shown in Fig. 1.

A systematic review and meta-analyses (Prisma) are an evidence-based minimum set of records for disclosure of systematic review and meta-analysis. The preferred reporting records emphasize the propagation of studies by analyzing randomly assigned records and can be utilized as a critical element for disclosing systematic reviews of different research types, predominantly estimating the intrusion. These guidelines are designed to assist authors to enhance the presentation of systematic review and meta-analysis and used for journal peer reviewers and

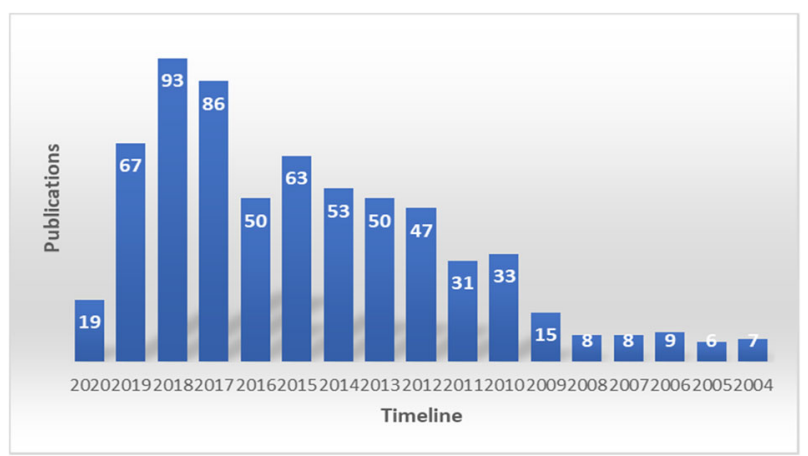

Fig. 1 Cumulative publications on the microneedle drug delivery system. The analysis was done by the PubMed database using the search term "microneedle drug delivery" [98] editors for critical evaluation of the published systematic review. It also delivers comprehensive procedures relating to the technique, including eligibility criteria, information source, search strategy to execute a systematic review, and meta-analysis [9].

In the past, a wide range of materials were used for the fabrication of MNs. Initially, MNs were fabricated using silicon [10-12], titanium oxide [13], stainless steel [14], ceramics [15], and glass [8]. Polymers play a vital role in the fabrication of MNs and a key pillar for clinical applications $[16,17]$. Biopolymers, predominantly carbohydrates, were considered over synthetic polymers because of their biocompatibility, low toxicity, biometric characteristics, and biodegradable properties [18-20]. The parade of carbohydrates existing in nature has permitted the fabrication of MNs with exceptional features [18-23]. Several reviews on microneedles exist, but none exhaustively concentrated on carbohydrate-based MNs and reviewed using PRISMA guidelines [9]. Hence, considering the existing significance and the extent of carbohydrates, this review discussed challenges during the fabrication of carbohydrate-based MNs for drug delivery. Finally, it is highlighted with the prospect and clinical presence of carbohydrate-based MNs.

\section{Methods}

\subsection{Eligibility criteria}

A literature search was performed on English language papers using the PRISMA guideline [9]. Peer-reviewed articles published in the year January 2000-May 2020 were included, and publications before January 2000 were excluded. Studies describing carbohydrate-based MNs and studies related to the in vitro, in vivo data of carbohydratebased MNs were chosen to be included. Articles published only in the English language were included.

\subsection{Search strategy}

A search of the PubMed database identified studies published until May 2020. MEDLINE, Scopus, Google Scholar, Web of Science, and gray literature were incorporated into the search strategy. The search terms included 'microneedle drug delivery' and 'carbohydrate-based microneedle'. It also included terms like clinical practices, bioavailability, fabrication, microneedle array, and patient compliance.

\subsection{Quality article and data analysis}

The article quality and references of relevant articles were assessed individually according to the PRISMA protocol criteria. The quality criteria used to describe the studies were 
Table 1 Description of criteria listed for the selection of records for review

Fig. 2 PRISMA flowchart for the records reviewed [9]

\begin{tabular}{lll}
\hline Sr. No. & Criteria & Description \\
\hline 1. & $\begin{array}{l}\text { Designing, evaluation, and } \\
\text { safety of microneedle }\end{array}$ & $\begin{array}{l}\text { - Was there a clear description of the fabrication, biopolymer } \\
\text { used, and compatibility of carbohydrate-based microneedle? } \\
\text { - Was there a clear description of the evaluation and application } \\
\text { of carbohydrate-based microneedle? }\end{array}$ \\
& $\begin{array}{l}\text { - Was a complete preclinical and clinical study described? } \\
\text { 2. }\end{array}$ & Preclinical and clinical presence \\
& &
\end{tabular}

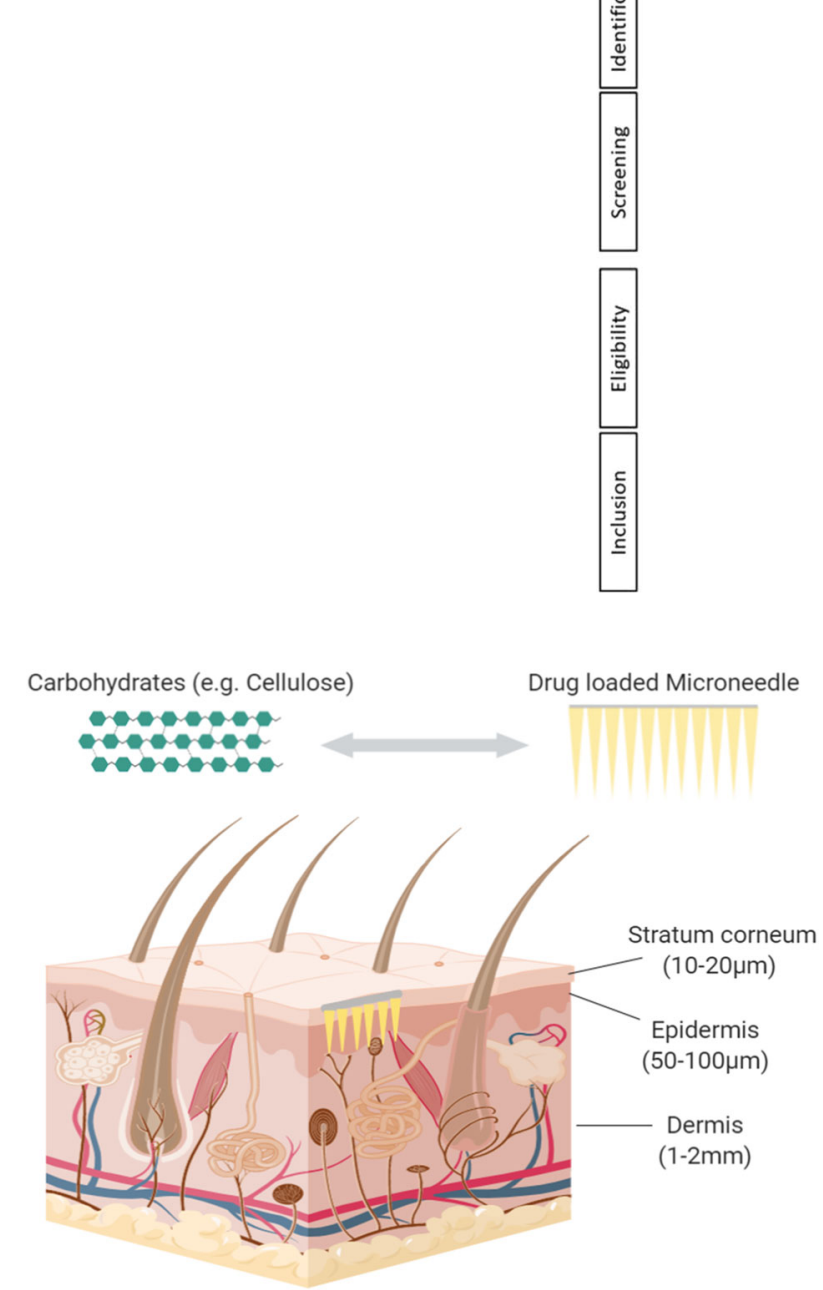

Fig. 3 Schematic representation of a microneedle inserted into the skin

biopolymers, design, evaluation, and safety of the microneedle, preclinical, and clinical presence. A detailed description of the criteria used for the qualitative assessment of the records is given in Table 1.

\subsection{Results of PRISMA analysis}

A literature search was conducted using PRISMA guidelines. Search strategies were set with different keywords and specific assessment criteria for inclusion and exclusion of

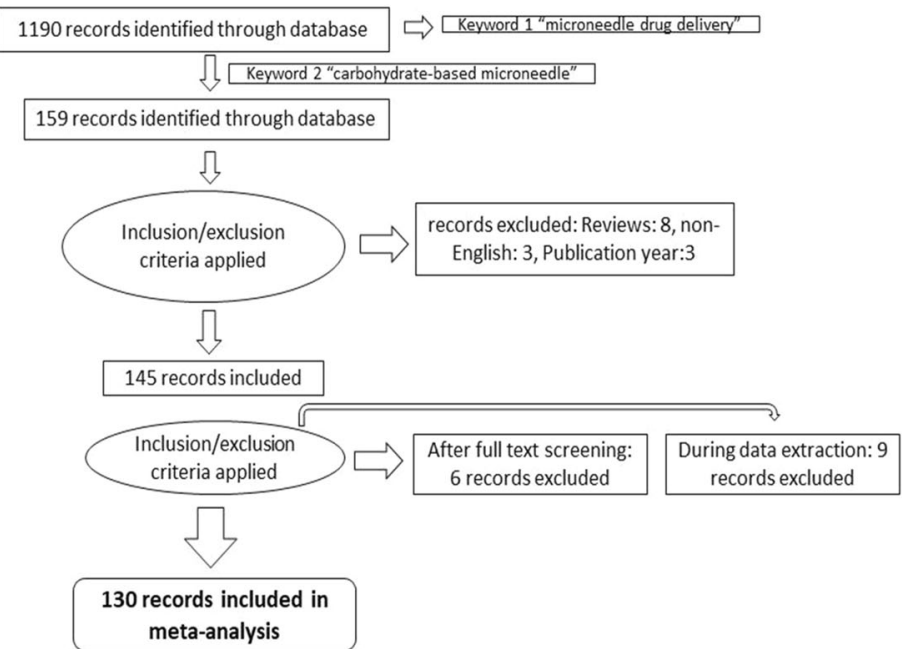

records, as shown in Fig. 2. As of 1190 records identified from prime research-comprehensive databases, 159 papers were retained to include the keyword "carbohydrate-based microneedle" in the search strategy. Fourteen records were excluded as they were formed in other languages and review articles to give 145 inclusions. According to the inclusion criteria given in Table 1, from the 145 inclusions, 15 papers were further excluded during full-text screening and data extraction as they did not describe carbohydratebased microneedles. Finally, a total of 130 records were considered for a systematic review.

\section{Results of Prisma analysis}

\subsection{Basics of microneedles}

\subsubsection{Descriptions and features}

Microneedles are microscale arrays designed to penetrate the skin's stratum corneum, forming microchannels through which active molecules diffuse passively (Fig. 3) [24-26]. Microneedles are $150-1500 \mu \mathrm{m}$ in length, $50-250 \mu \mathrm{m}$ in width, and 1-25- $\mu \mathrm{m}$ thick tips, enhancing the drug efficacy and transcutaneous flux of pharmaceuticals [27].

Generally, MNs are categorized based on their assembly (Fig. 4 (A)), design (Fig. 4 (B)), and tip shape (Fig. 4 (C)). 
Fig. 4 Schematic representation of MNs A MN assembly (a) inplane and (b) out-of-plane. B The design of out-of-plane MNs is defined as (a) hollow and (b) solid. C Microarrays are (a) cylinder-shaped, (b) conical, (c) pyramidal, (d) and (e) pentagonal-based pointy and tapered tip, respectively
(B)

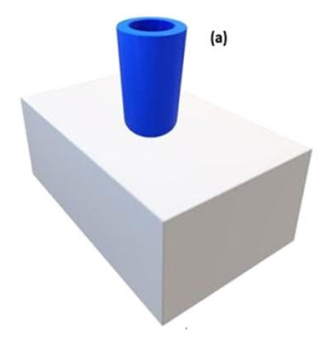

(A)

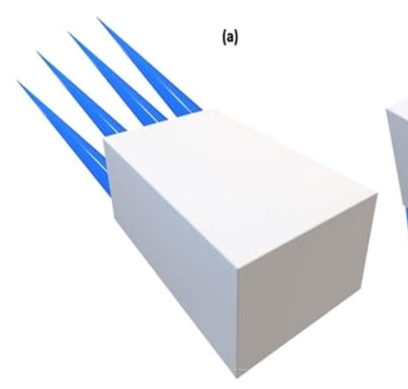

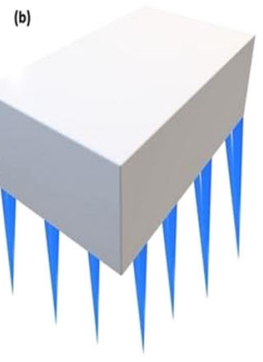

(b)

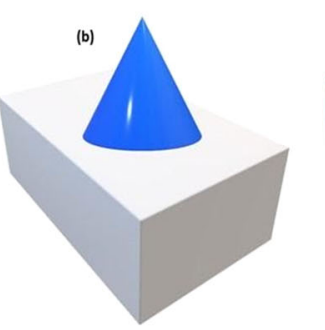

(a)

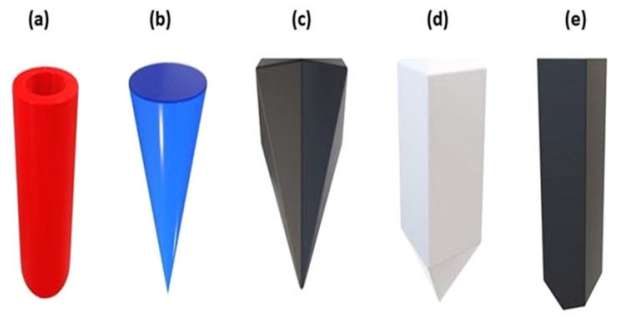

(C)
Fig. 5 Different types of MNs according to the drug delivery approaches a solid, b coated, c dissolving, $\mathbf{d}$ hollow, and e hydrogel-forming MNs

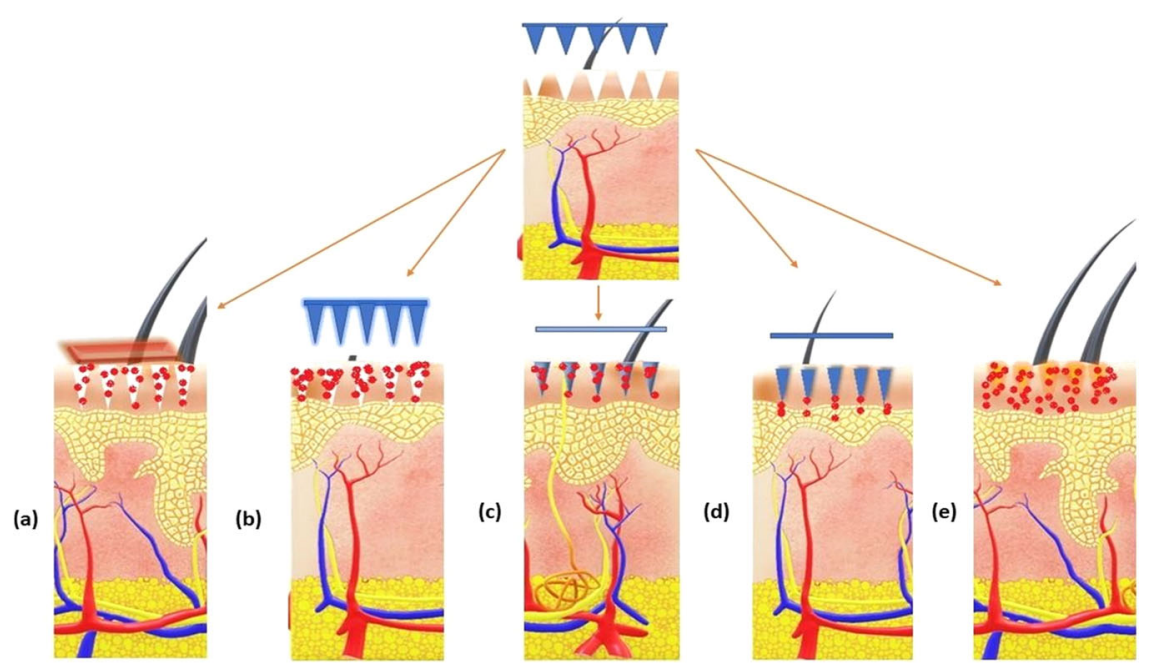

MNs are manufactured into two elementary designs-inplane and out-of-plane. The arrays of in-plane MNs (Fig. 4 (A) a) are parallel to the surface, whereas those of out-ofplane MNs (Fig. 4 (A) b) rise vertically from the base. The out-of-plane MNs can further be classified as hollow (Fig. 4 (B) a) or solid-shape MNs (Fig. 4 (B) b). Microneedle tips could be cylindrical (Fig. 4 (C) a), conical (Fig. 4 (C) b), pyramidal (Fig. 4 (C) c), and pentagonal with either a pointy or a tapered tip (Fig. 4 (C) d and e), accessible in many more forms $[8,28]$.

Microneedle arrays are optimized by choosing the array dimensions and design, which might inflict less pain, good mechanical strength, and drug delivery [28]. Gills H.S investigated that a decrease in microneedle length and microarrays reduces pain and establishes that there is no role of microneedletip angle, thickness, and width in the degree of pain caused by the application of MNs [29].

\subsubsection{Approaches for drug delivery with MNs}

The delivery of drug-using MNs is characterized according to five different types and related forms of drug delivery (Fig. 5, Table 2).

3.1.2.1 Poke-and-patch approach The first method is to poke the epidermis layer by microarray, which produces microchannels for drug delivery, subsequently detaching the microarray. Then, a transdermal patch is applied above it. Furthermore, to improve permeability, the electro field may be used. Solid microneedles follow this approach for the enhancement of skin permeability.

3.1.2.2 The coat-and-poke approach The second way is to coat the microneedle arrays with the drug dispersion. The coated drug dissolves after piercing the coated microneedles 


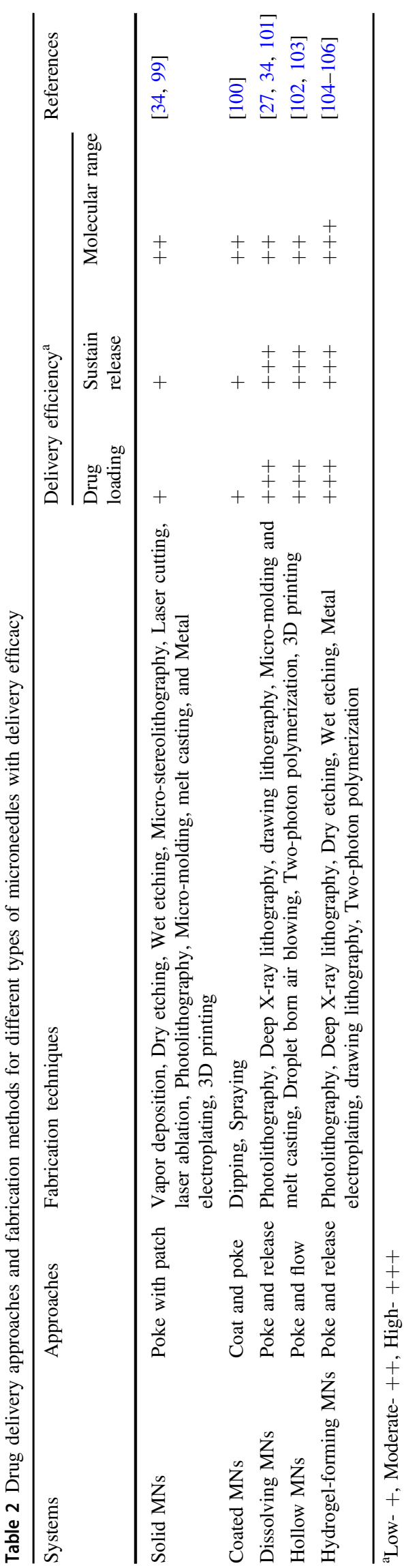

into the skin. Microarrays can be covered with several compounds, including small molecules, proteins, plasmid DNA, virus particles, polymer nanoparticles, and water-soluble compounds.

3.1.2.3 The poke-and-release approach As a novel alternative to coated microneedles, the drug is encapsulated within microneedles made up of polymers and polysaccharides for rapid and sustained release in the skin. As a result, after piercing into the skin, the microneedles dissolve or degrade, releasing the encapsulated drug in a controlled manner.

3.1.2.4 The poke-and-flow approach In contrast to solid microneedles, hollow microneedles offer extra abilities and fewer difficulties. Hollow microneedles have complex fabrication processes with intrinsically weaker and sophisticated geometry. They permit the liquid formulations, which allow diffusion of the drug rapidly or with controlled flow rates, as required, but the rate-limiting step in hollow microarrays is the maintenance of flow rate.

\subsubsection{Mechanical characterization of microneedles and safety evaluations}

Mechanical characterization is a crucial step in the successful fabrication of MNs. Extensive stress during the insertion and removal of MNs is applied. Hence, it is essential to perform mechanical characterization and analyze the safety of MNs [11]. A variety of tests available to check mechanical strengths [30], are as given below.

3.1.3.1 Axial force mechanical test In this test, force is applied to the MNs perpendicular to the base plate (Fig. 6a) [31]. The applied force can be analyzed using a mechanical station, which details both displacement and force against a hard surface at a definite rate $[32,33]$. If a fracture occurs, a rapid drop can be seen in the force-displacement curve produced and considered as failure force [33]. A single microneedle $(\mathrm{MN})$ is used to analyze failure force, which does not accurately simulate the pressures faced during insertion into the skin [30, 34, 35]. After piercing MNs into the skin, the forces are dispersed over a greater MN area as the flexible skin encases the MNs. The said axial force test is often used to assess polysaccharide MNs. Table 3, a summary of the published data about the mechanical strength of polysaccharide MNs [36].

3.1.3.2 Transverse force and shear strength Due to skin irregularities and elasticity, frequent incomplete insertion and bending of MNs arrays were observed. Thus, a transverse fracture force test is essential to investigate the performance of MN during application [32, 33]. The test is carried out on a mechanical test station; a transverse force 
(a)

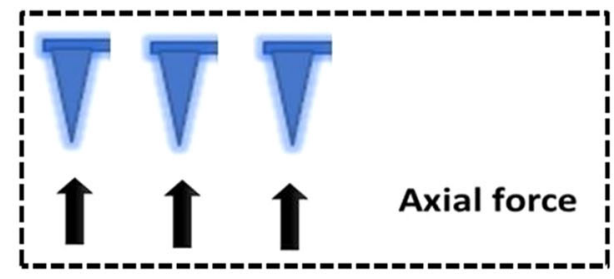

(c)

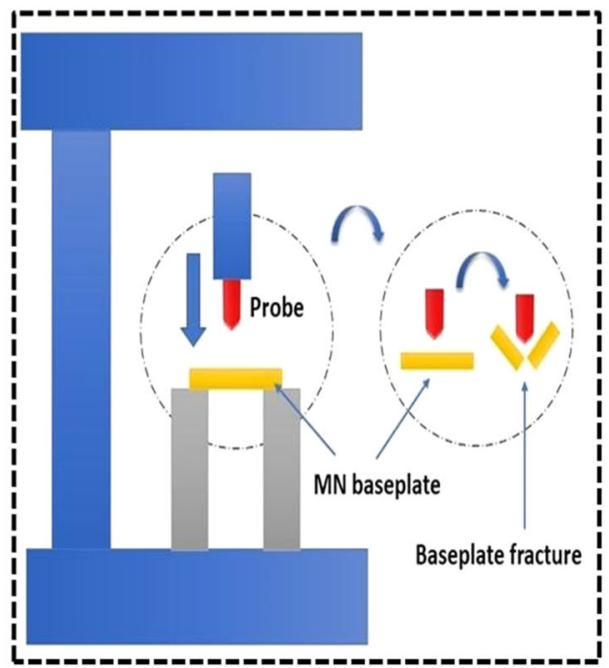

(b)

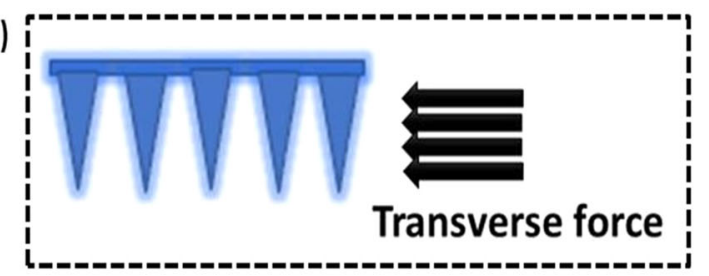

(d)

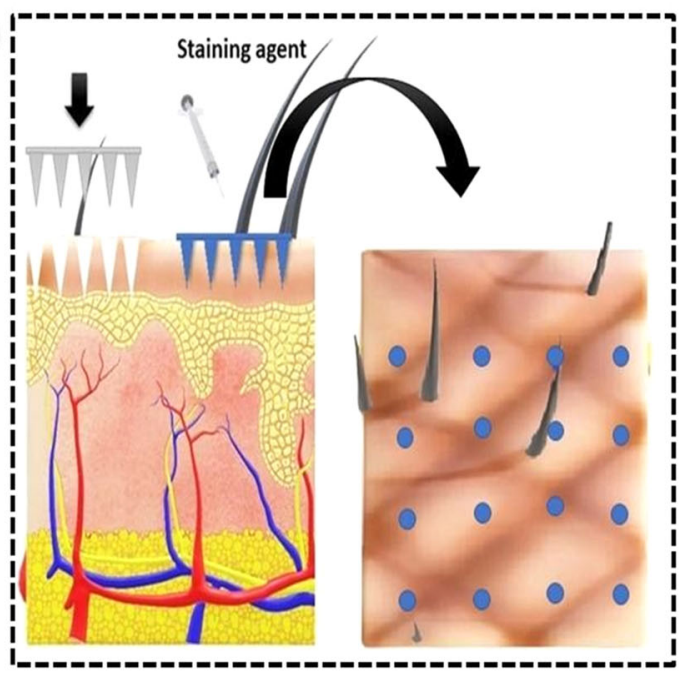

Fig. 6 Illustration of the mechanical properties of MNs. a Axial force test. b Transverse force test. $\mathbf{c}$ Base-plate strength and flexibility tests. d Microneedle-insertion measurement by staining

Table 3 Failure force after an axial force load of carbohydrates

\begin{tabular}{lll}
\hline Composition of MN & Failure force & Reference \\
\hline Hyaluronic acid (HA) & $\geq 0.05$ & {$[107]$} \\
& $0.4-0.6$ & {$[108]$} \\
& 0.18 & {$[109]$} \\
HA with Epidermal growth factor & $0.63-0.78$ & {$[43]$} \\
Sodium hyaluronate with & $\geq 0.08$ & {$[110]$} \\
Enterovirus & & \\
Lysozyme loaded HA & 0.20 & {$[81]$} \\
Methacrylate HA & $\geq 0.15$ & {$[48]$} \\
Sodium alginate & Transverse force & {$[32]$} \\
Chitosan & failure 0.04 & \\
Magnetic graphene quantum dots & $\geq 0.16$ & {$[82]$} \\
loaded Chitosan & & {$[111]$} \\
Carboxymethyl Cellulose & $0.5-0.8$ & {$[108]$} \\
\hline
\end{tabular}

(normal to the MN y-axis) is employed at a definite point on the MN array until the MN fractures [33]. Again, a rapid reduction in the force-displacement curve shows the MN defect [31]. This test is carried out on a row of MNs rather than a single array, which calculates transverse fracture force per MN (Fig. 6b). According to the literature, this test's critical drawback is that the metal probe should be parallel with the MN array manually, which leads to inaccuracy $[31,32]$.
3.1.3.3 Base-plate strength and flexibility tests Assessment of base-plate strength is crucial as the abovementioned mechanical strength. Fracture of the base plates during piercing to the skin is not acceptable. Hence, base plates should be flexible enough to consent to the skin structure deprived of rupturing (Fig. 6c). A three-point bending test can be used to analyze base-plate strength. Donnelly et al. utilized a Texture analyzer to apply force with a metal probe to the base plate sitting between two aluminum blocks. Also, the base-plate flexibility is evaluated with the bending fracture of MNs [31].

\subsubsection{Microneedle insertion measurement Several} techniques are applied to evaluate the insertion of MNs into the skin. Staining is a commonly used qualitative technique that stains epidermis cells, not microchannels created in the stratum corneum (Fig. 6d) [37-39]. Other qualitative methods are transepidermal water loss $[39,40]$ and electrical impedance [34, 35, 41] after poking the skin. Confocal microscopic imaging [36], histological cryosectioning with adjunct staining [41], and optical coherence tomography [31] was used, which estimates quantitative insertion-depth data. Lately, Larraneta et al. projected an artificial membrane for $\mathrm{MN}$ insertion studies [42].

Factors like different materials and geometry of MN interrupt the insertion studies, using various experimental 
protocols and skin models. Thus, the standard protocol is crucial to assess mechanical performance.

3.1.3.5 Microneedles' safety Microneedles are based on the principle of piercing the outermost skin layer, which is not similar to the conventional transdermal patch. The suitability of microneedles has been evaluated and predicted on the degree of adverse effects, namely, itching, scaling, prickling, stinging, tightness, burning, edema, and erythema. No one has reported carbohydrate microneedle-related local infection. The disturbance may occur during the piercing or compatibility of the material used for fabrication with skin or residual solvents in the needles. The microneedle is designed to avoid pain while piercing. A formed microchannel must be reclosed in the short term to eradicate the contamination. The microneedles and formulation should be biocompatible with the skin. Modepalli et al. studied the safety and toxicity of hydrogel-forming microneedles on the human skin. They stated no toxicity in cell lines due to the microneedle [37]. Sodium hyaluronate and polyvinyl pyrrolidone used to fabricate dissolving microneedles were examined for cytotoxicity using an MTT assay to assess cell viability of more than $87 \%$ at the end of $72 \mathrm{~h}$. The biological safety of ibuprofen sodium-loaded hydrogel-forming microneedles was studied and observed that no bioburden was traced [16]. Drug-loaded hyaluronic acid microneedles led to no allergic or irritant-contact dermatitis, hence, considered as a safe product for human use [43].

In certain cases, MNs pierce the epidermis and dermis layer, generally sterile areas of the body [7]. Thus, MNs must not contain microbes that may lead to systemic infections. Also, microbial penetration through $\mathrm{MN}$-created holes is significantly low than conventional hypodermic needle puncture. The possible solution may be the production of sterile MNs, but the sterilization method should be carefully considered to evade alteration of key features of the product and increase production cost. For instance, aseptic manufacturing will be costly, terminal sterilization with moist heat or microwave heating, and gamma radiation could damage the MNs. McCrudden et al. evaluated the effect of different sterilization methods on dissolving and hydrogel-forming MNs [16]. Thus, safety studies can be performed for the polymeric matrix which will be used for the fabrication of MNs.

\subsubsection{Carbohydrate-based microneedles}

Carbohydrates play a quintessential role in the fabrication of MNs, and thus form the emphasis of this review. Carbohydrates, such as sugars, hyaluronic acid [44, 45], cellulose [46, 47], and chemically modified methacrylate hyaluronic acid [48], carboxymethylcellulose [49, 50], are utilized alone, in a blend, or as a composite. They are similar to the extracellular matrix and are simply recognized and accepted by the human body [51]. They are eliminated by metabolism and excretion through the renal system, evading tissue accretion [52]. Carbohydrates are approved by the US Food and Drug Administration (US FDA) and classified as generally recognized as safe (GRAS) [53, 54].

Carbohydrates reveal an enormous structural disparity and several intrinsic characteristics, which impact the mechanical properties and invasion ability of MNs and influence the biological potency and durability of the therapeutic agent [55-57]. Certain traits, like the polymer's weight, swelling index, and an interface between the polymer and active agent, can stimulate and alter the drug-release rate $[2,58,59]$. The innumerable topographies impact their in vivo behavior and can be grouped into dissolvable (dextran, sodium chondroitin sulfate, and hyaluronic acid), biodegradable (chitin, starch), and swellable polymeric microarrays (methacrylate hyaluronic acid) as summarized in Table 4. The following section gives an overview of various carbohydrates. Table 5 highlights a few of the current examples of carbohydrate-based MNs

Table 4 Merits and demerits of dissolvable, biodegradable, and swellable carbohydrate-based microneedles [54]

\begin{tabular}{|c|c|c|}
\hline Microneedle design & Merits & Demerits \\
\hline Dissolvable Microneedle & $\begin{array}{l}\text { - Allow fast drug release as the rate of dissolution is } \\
\text { increased } \\
\text { - Encapsulation or coating can improve drug } \\
\text { loading } \\
\text { - Precise drug loading can be achieved } \\
\text { - Generally used for sustained drug release }\end{array}$ & $\begin{array}{l}\text { - A patch can not be detached before the complete } \\
\text { dissolution of microneedles }\end{array}$ \\
\hline Biodegradable Microneedle & $\begin{array}{l}\text { - Encapsulation or coating can improve drug } \\
\text { loading } \\
\text { - Precise drug loading can be achieved } \\
\text { - Attachment of Drug reservoir is allowed }\end{array}$ & $\begin{array}{l}\text { - After few days of degradation, polymer residue } \\
\text { can be detected in the skin }\end{array}$ \\
\hline $\begin{array}{l}\text { Hydrogel forming/Swellable } \\
\text { Microneedle }\end{array}$ & $\begin{array}{l}\text { - After removal, Smoothness prevents reinsertion } \\
\text { - After few days of degradation, polymer residue } \\
\text { can't be detected in the skin } \\
\text { - If necessary, treatment can be stopped }\end{array}$ & $\begin{array}{l}\text { - Inadequate drug loading } \\
\text { - Bioactivity of a drug may hamper due to cross- } \\
\text { linking of the polymer }\end{array}$ \\
\hline
\end{tabular}




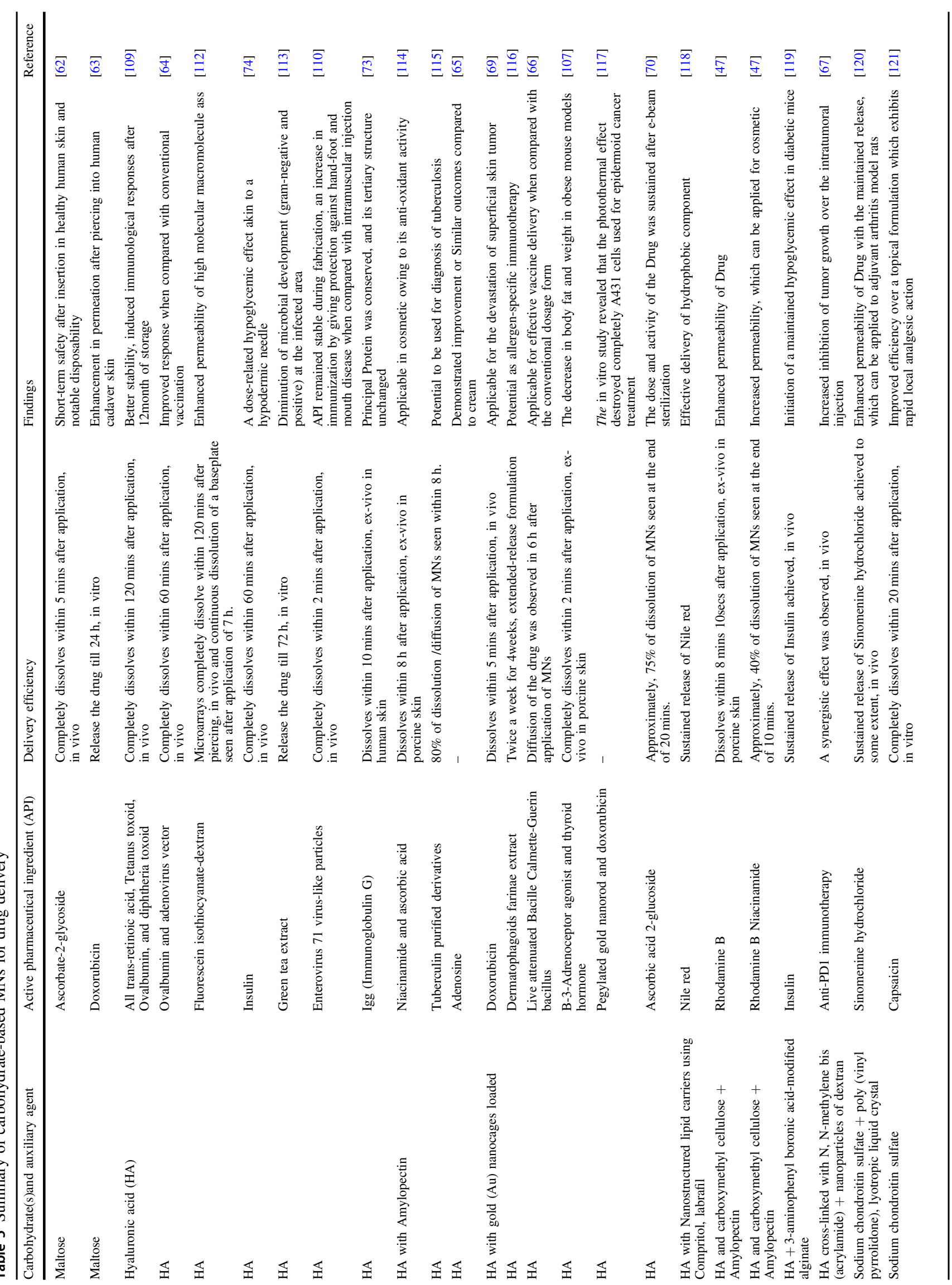




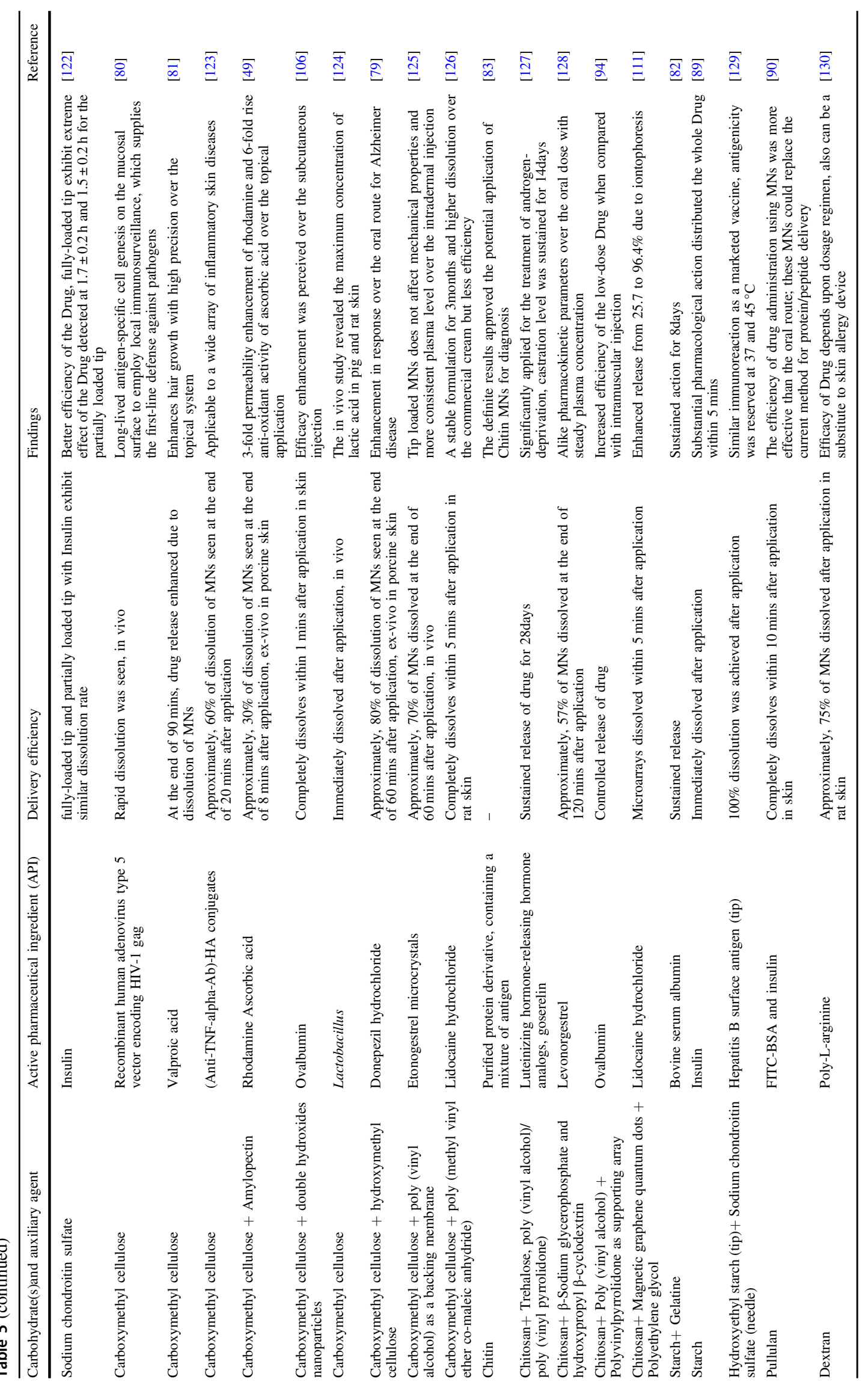


Table 6 list of active and completed clinical trials [91]

\begin{tabular}{|c|c|c|c|c|c|}
\hline Carbohydrate & Condition & Identifier & Titles & Year & Status \\
\hline HA & Crow's Feet Wrinkles & NCT02497846 & $\begin{array}{l}\text { TEOSYAL PureSense Redensity }[\mathrm{I}] \text { Injection Using MicronJet } \\
\text { Needle in the Treatment of Crow's Feet Wrinkles }\end{array}$ & 2016 & Completed \\
\hline HA & Psoriasis & NCT02955576 & Microneedle Patch for Psoriatic Plaques & 2017 & Active \\
\hline HA & $\begin{array}{l}\text { Vitiligo - Macular } \\
\text { Depigmentation }\end{array}$ & NCT02660320 & $\begin{array}{l}\text { Comparison of the Efficacy of Micro-holes vs. Laser-assisted } \\
\text { Dermabrasion for Repigmenting in Vitiligo Skin (Dermabrasion) }\end{array}$ & 2018 & Active \\
\hline Starch & $\begin{array}{l}\text { Primary Axillary } \\
\text { Hyperhidrosis }\end{array}$ & NCT03054480 & $\begin{array}{l}\text { Fractional Micro-Needle Radiofrequency and Botulinum } \\
\text { Toxin A for Primary Axillary Hyperhidrosis }\end{array}$ & 2017 & Completed \\
\hline Starch & $\begin{array}{l}\text { Primary Axillary } \\
\text { Hyperhidrosis }\end{array}$ & NCT02823340 & $\begin{array}{l}\text { Fractionated Microneedle Radiofrequency for Treatment of Primary } \\
\text { Axillary Hyperhidrosis }\end{array}$ & 2016 & Active \\
\hline
\end{tabular}

described in the literature detailing their primary element, a therapeutic agent, and their biomedical applications.

3.1.4.1 Sugars Sugars present an attractive resource for the fabrication of biomolecules delivering MNs. Also, the combination with other polymers may enhance the mechanical strength and stability of MNs. Maltose is the most widely used sugar for the fabrication of MNs and is classified as GRAS [60]. Additionally, mannitol, trehalose, sucrose, xylitol, and galactose also can be utilized to fabricate MNs [61]. Some studies on sugar MNs are carried out by Miyano et al., who designed ascorbate-2-glycoside-loaded sugar MNs that depicted short-term safety in healthy human skin [62], while Nguyen et al. fabricated doxorubicin-loaded maltose MNs that showed the enhancement in permeation after piercing into human cadaver skin [63].

3.1.4.2 Hyaluronic acid (HA) Hyaluronic acid is a crucial element of the extracellular matrix and cartilage, which has mucoadhesive properties [2, 54]. HA is a negatively charged biopolymer, and its salt has a high solubility in water. Matsuo et al. fabricated dissolvable HA MNs of different sizes that dissolved within 5 mins [64]. Kang et al. [65] prepared adenosine-loaded hyaluronic acid MNs for cosmetic purposes and observed that needles were completely dissolved within 15 mins after inserting into the porcine skin, which showed better results than when compared with the topical cream. Rather than adding the therapeutical element into the matrix, Liu et al. [44] fabricated MNs with tips loaded with hyaluronic acid dissolved within the $30 \mathrm{~s}$. In this study, topical delivery of exendin-4 was studied, and permeability was carried out by labeling with fluorescein isothiocyanate (FITC). The results of in vivo studies depict burst release within the first $30 \mathrm{~s}$, and almost-labeled dextran was dissolved within 5 min. MNs generated equivalent pharmacokinetic profiles when compared with subcutaneous injection in type-2 diabetic rats. Thus, it can be a substitute for type- 2 diabetes therapy.

In a separate study, Chen et al. [66] fabricated Calmette-Guerin bacillus-loaded HA MNs, for tuberculosis prevention, which dissolved within 10-15 mins. As stated by the World Health Organization (WHO), the Calmette-Guerin bacillus vaccine is stable at $2-8{ }^{\circ} \mathrm{C}$. This research reported good stability at ambient temperature and quick onset of action for the undeveloped area. For nanomedicine delivery, Wang et al. [67] formulated $\mathrm{pH}$-sensitive dextran nanoparticles loaded in cross-linked HA MNs to treat skin cancer. The nanoparticles comprised dextran derivative, alginate, glucose oxidase, and aPD1 in an acid-degradable polymeric matrix. When applied to the melanoma site, this microdevice converts glucose to gluconic acid, producing an acidic environment and subsequent antibody release.

Another study involved direct incorporation of cells and polymer, like the adipose-derived stromal vascular fraction cells carrying HA MNs, for diabetic wound healing. Cells loaded with HA MNs depicted improved wound healing compared with HA MNs and isolated sections, proposing an alternative approach [68]. In a different light, Park et al. designed amylopectin MNs to deliver essential nutrients, specifically niacin and ascorbic acid, wherein the amylopectin was used to enhance the mechanical strength of HA MNs in a ratio of 1:2.3 (HA:amylopectin). The higher concentration of amylopectin resulted in a stiffer and brittle structure, tough to remove from the mold without breaking. Dong et al. [69] formulated Au nanocages and doxorubicin-loaded HA MNs as $\mathrm{Au}$ nanocages reinforce the mechanical endurance and photothermal effect of a drug on exposure to infrared light to results in the eradication of exterior skin tumors.

In another approach to customizing drug delivery, Kim et al. [70] designed HA MNs with trehalose and polyvinylpyrrolidone to facilitate peptide delivery. The study implied that polyvinylpyrrolidone prevents peptide agglomeration and enzymatic degradation, thus enhancing the dissemination of the drug into the systemic circulation. MNs for disease diagnosis were also performed. Chang et al. [48] developed swellable MNs with methacrylate HA for metabolic detection, wherein the MN patch extracts sufficient interstitial fluid in a shorter time without the need of any external device.

Cross-linking of HA may cause swelling and tailor the degradation or drug delivery [59, 71]. Zhang et al. [59] 
designed cross-linked HA MNs with 1,4-butanediol diglycidyl ether, enhancing the mechanical strength of MNs and lowering degradation of the matrix, thus, an excellent prospect for prolonged drug delivery. Larraneta et al. defined an additional cross-link, Gantrez S97, who developed hydrogels with HA and a copolymer of methyl vinyl ether and maleic acid, respectively. Gantrez concluded that esterified cross-linked HA MNs might release up to $48 \mathrm{~h}$, which eased microbial infection [72].

The incorporation of proteins and peptides was also studied. Monkare et al. developed HA MNs loaded with $\mathrm{IgG}$, which recovered $82 \%$ of the protein with no change in the tertiary structure after fabrication [73]. Liu et al. studied the stability of fabricated insulin-loaded MNs at different temperatures for a month and reported MN stability, with more than $90 \%$ insulin detection. Insulin release from such MNs was enhanced after storage and resulted in a glycemiclevel reduction from 43 to $88 \%$ [74].

In different prospects, HA's feasibility was demonstrated by e-beam sterilization, which impeded the ascorbic acid 2glucoside degradation of HA MNs as the dissolution rate and drug release, structural features, and fracture force remained unaffected, without activity loss of capsulated active elements [70].

3.1.4.3 Chondroitin sulfate MNs Sodium chondroitin sulfate is a hydrophilic component [75] of the extracellular matrix and cartilage [2,59], which is immeasurably used for fabrication. Fukushima et al. fabricated human growth hormone, desmopressin-loaded sodium chondroitin sulfate, and dextran MNs, which established that dose and concentration were directly proportional to each other [57]. Ito et al. developed leuprolide acetate-loaded sodium chondroitin sulfate MNs that delivered drugs within 15 mins when applied to rat skin [76].

3.1.4.4 Cellulose-based MNs Hydrophilic polymers like carboxymethyl cellulose and (hydroxypropyl) methylcellulose are predominantly utilized because of their several features. These biopolymers are used as thickening agents, binders, stabilizers, and film-forming agents [77, 78]. Kim et al. fabricated donepezil hydrochloride array tip-loaded (hydroxypropyl) methylcellulose MNs to treat Alzheimer's disease. In vivo studies revealed that the release of the drug was achieved within 5 mins after insertion, and microarrays were completely dissolved within 15 mins in the skin [79].

On the other hand, Zaric et al. [80] fabricated human adenovirus type-5 vector-loaded carboxymethyl cellulose and sucrose (protein stabilizer) MNs for vaccine delivery. This research established the potential of MNs to sustain the antigenicity of attenuated vaccines after freeze-drying. Another study was performed on Lactobacillus-loaded carboxymethyl cellulose MNs, enhancing local skin health and rat's immune functions [80], while Lahiji et al. fabricated valproic acid-loaded carboxymethyl cellulose MNs to treat hair regrowth. Enhancement in the valproic acid release was observed and compared with the topical formulation, which elevates hair follicles' regrowth [81].

3.1.4.5 Chitin and chitosan MNs Chitin and chitosan, after cellulose derivatives, are the widely used biopolymers produced by the deacetylation process. Chitosan comprises a high-density positive charge due to its acidic nature, allowing tissue and mucoadhesion [82-84]. Degradation of chitosan occurs by hydrolysis of acetylated residues, and its degradation rate is related to molecular mass and the degree of deacetylation [52]. Apart from these, the FDA has identified chitosan as GRAS, used for wound dressing and cartilage repair [54, 85, 86], and utilized for the fabrication of MNs for controlled and sustained drug delivery [85].

Jin et al. formulated chitin MNs coated with antigens, a convenient diagnostic tool for tuberculosis. Chitin MNs were water-insoluble, mechanically robust, physiologically inert, and exhibited a lower swelling index. Chen et al. [83] prepared chitosan MNs to allow the sustained release of bovine serum albumin (BSA). These chitosan MNs when pierced into porcine skin showed a $20 \%$ burst release of BSA after 30 mins. Subsequently, 95\% of BSA was released within eight days. Within this period, chitosan MNs soften and break after insertion, which results in the retention of some polymeric pieces in the skin [83]. Besides this, Chen et al. [82] also developed tip-loaded chitosan MNs comprising model antigen ovalbumin for sustained delivery. These effective chitosan MNs contained biodegradable baking of poly (L-lactide-co-D, L-lactide), overcoming impression after piercing, which is not detected post $6 \mathrm{~h}$. The in vivo study revealed that $50 \%$ of the antigen was released within the first two days, and a slight fluorescence was detected in three weeks [82].

3.1.4.6 Starch-based MNs Starch is a biodegradable polymer extensively used due to its ease of processing and filmogenic ability for biomedical purposes [87]. While formulating, owing to its brittle behavior, starch is combined with other polymers [88]. Ling et al. substantially mixed starch with gelatine to transmit insulin, which loaded within 5 mins. Captivatingly, more than $90 \%$ of insulin was stable at ambient temperature for 30 days, specifying costeffectiveness and convenience after application [89].

Pullulan (PL), a hydrophilic biopolymer formed by the yeast-like fungus Aureobasidium pullulans in starch and sugar cultures, plays a crucial role in biomedical applications. This biopolymer has unique characteristics, such as oxygen-barrier property, mechanical robustness, chemically inert, transparent, and filmogenic ability with no toxicity or mutagenicity. Hence, PL is an outstanding 
candidate for the fabrication of dissolvable MNs. Vora et al. fabricated PL MNs to deliver proteins and peptides, namely FITC-BSA and insulin. Ex vivo studies demonstrate protein/peptides detected within 15 mins when applied to porcine skin [90].

\subsubsection{Clinical presence and regulatory requirement for commercialization}

Many nonclinical studies were conducted for carbohydratebased microneedles, which revealed enhancement in efficiency and permeability, but only a few accomplished positive clinical testing results. Table 6 summarizes active and completed clinical trials using carbohydrate-based microneedles [91]. Since microneedles are novel drug delivery systems, there are no particular requirements established to date. The conventional transdermal patch is simply applied to the skin's exterior surface, whereas MNs pierce the stratum corneum and even interrupt the epidermis and dermis. This mechanism motivates the necessity of regulatory demands. Henceforth, new provisions should be defined for the MN, apart from the existing transdermal patch. Some essential regulations that need to be considered with the commercialization of $\mathrm{MN}$ arrays are given below:

1. Materials, length, sharpness, needle characteristics, and geometry should be correctly designed

2. The MN arrays should retain satisfactory microbiological standards

3. The MN arrays should keep the uniformity of content

4. Quality manufacturing, safety, and packaging should be maintained

5. Safe and nonhazardous procedures should be drawn for $\mathrm{MN}$ arrays

6. A self-disabling mechanism assuring a single use may require the $\mathrm{MN}$ arrays to avoid reuse by patients or others.

7. If $\mathrm{MN}$ arrays are reusable, cleaning information should be provided

8. For long-term use, material safety should be considered with precision

9. Labeling should contain instructions for use

10. MN arrays should be used with a proper applicator for proper insertion and pain-free delivery. Also, arrays should give reproducible results without complications

11. Immunological safety assurance should be considered

\section{Conclusion and future perspective}

Drug delivery via the transdermal route has seen incredible development, among which the microneedle arrays facilitating drug infusion via forming several microchannels in the stratum corneum have grown exponentially over the past two decades. In the past fifteen years, the aspect of material science has transformed radically, and the utilization of natural polymers for recuperative purposes would be a critical success [53, 92, 93].

Carbohydrate usage presents an inclusive array of benefits owing to their intrinsic physiological compatibility, degradability, nontoxic, and sustainable nature. The inherent variation in carbohydrates, stemming primarily due to animal and plant origin, absence of standardization, and variation in appearance, with time or development, are few aspects that play a significant drawback role during commercialization [92]. The appropriate assessment and complete description of carbohydrates are necessary for analysis to overcome these drawbacks. Additionally, a significant feature emphasizes the probability of degeneration, decay, or adulteration of these resources during mining and development. The mechanical properties of carbohydrates can be enhanced by integrating with additional biopolymers [89], or nanosystem [69], and also cross-linking [94], which allows rupture of skin. The batch-to-batch variation impacts on mechanical qualities of a biopolymer.

Restructuring the study protocols as per the properties of the carbohydrates is essential. For instance, in moistureabsorbing polymers, assessments forecasting storage in water-resistant packages should be conducted. Along the same lines, considering the probabilities of utilizing these microarrays in states with high RH like the WHO climatic zone IV, deficiency of availability, and setups, appropriate contingencies should be planned [89]. The critical feature of MNs is the ease of self-administration. For bulk production and self-utilization, a unique applicator should be accompanied to allow adequate application, resulting in increased costs, but it is essential to ensure a preset force to assure skin insertion and its consequent advantages. Instability of some drug molecules to the fabrication step necessitates stabilizers into the polymeric formulation, thus stabilizing the drug during fabrication and long-term storage.

The actual application of MNs delayed as the regulatory guidelines are ongoing. Still, the academy is bringing novel instigating records in this zone, which highlights the difficulties during developments. The formation of policies to manufacture and analyze MNs is authoritative to ensure specifications and precision during production. Larraneta et al. [95] explained the need for specification for the analysis of MNs. The small MN tips are safe and minimally invasive. The critical principle of MNs is piercing the skin by generating microchannels, which reconcile after a few hours and release the active medicament [96]. However, the skin's microchannels may allow bacteria entry, though the probability of bacterial contamination is significantly lesser than conventional injection [97]. The incidence of infection 
can be reduced by applying an alcoholic solution before applying MNs [96]. Piercing of MNs provides a proinflammatory microenvironment and immunological effects when applied frequently. Thus, the efficacy of MNs can be regulated by the skin's mechanism. Currently, applicators are used to pierce the MN patch in the skin with a defined force. Variability can be seen when applied by a different candidate. The responsive biomarkers are used to assure that MNs are effectively applied.

Sterilization of the MNs is a crucial step that impacts the stability of the active pharmaceutical agent. Concerning the storage condition, drug-loaded MNs must be stable at ambient temperature for their intact mechanical properties and pharmacological performance. Another critical aspect emphasizes MN arrays' disposal, which may transfer blood-borne disease through blood or ISF [97]. Nanocarriers or nanostructured polymer loaded carbohydrate MNs are widely used for drug delivery and diagnosis. This technique can be a substitute for the conventional dosage. Nowadays, MNs can detect $\mathrm{pH}$ or change in temperature.

In conclusion, sophisticated design and impressive fusion of carbohydrate-based MNs effectively deliver several active pharmaceutical agents with a broad spectrum of applications in various zones. Carbohydratebased MNs have a fundamental part in wellness management, which provides stimulating revolutions in drug delivery. In these arrays, it is anticipated that such designs might be legalized in clinical practice, fetching motivation from nature into day-to-day drug delivery applications in a couple of years.

Acknowledgements This research was supported by the Science and Engineering Research Board, File Number: CRG/2018/003176.

\section{Compliance with ethical standards}

Conflict of interest The authors declare no competing interests.

Publisher's note Springer Nature remains neutral with regard to jurisdictional claims in published maps and institutional affiliations.

Open Access This article is licensed under a Creative Commons Attribution 4.0 International License, which permits use, sharing, adaptation, distribution and reproduction in any medium or format, as long as you give appropriate credit to the original author(s) and the source, provide a link to the Creative Commons license, and indicate if changes were made. The images or other third party material in this article are included in the article's Creative Commons license, unless indicated otherwise in a credit line to the material. If material is not included in the article's Creative Commons license and your intended use is not permitted by statutory regulation or exceeds the permitted use, you will need to obtain permission directly from the copyright holder. To view a copy of this license, visit http://creativecommons. org/licenses/by/4.0/.

\section{References}

1. Anselmo A, Mitragotri S. An overview of clinical and commercial impact of drug delivery systems. J Controlled Release. 2014;190:15-28. https://doi.org/10.1016/j.jconrel. 2014.03.053.

2. Zhang Y, Chan H, Leong K. Advanced materials and processing for drug delivery: The past and the future. Adv Drug Deliv Rev. 2013;65:104-20. https://doi.org/10.1016/j.addr.2012.10.003.

3. Wiedersberg S, Guy R. Transdermal drug delivery: $30+$ years of war and still fighting! J Controlled Release. 2014;190:150-6. https://doi.org/10.1016/j.jconrel.2014.05.022.

4. Kurmi B, Tekchandani P, Paliwal R, Paliwal S. Transdermal drug delivery: Opportunities and challenges for controlled delivery of therapeutic agents using nanocarriers. Curr Drug Metab. 2017; 18:481-95. https://doi.org/10.2174/1389200218666170222150555.

5. Watkinson A, Kearney M, Quinn H, Courtenay A, Donnelly R. Future of the transdermal drug delivery market - have we barely touched the surface? Expert Opin Drug Deliv. 2015;13:523-32. https://doi.org/10.1517/17425247.2016.1130034.

6. Ita K. Transdermal drug delivery: progress and challenges. J Drug Deliv Sci Technol. 2014;24:245-50. https://doi.org/10. 1016/s1773-2247(14)50041-x.

7. Tuan-Mahmood T, McCrudden M, Torrisi B, McAlister E, Garland M, Singh T, et al. Microneedles for intradermal and transdermal drug delivery. Eur J Pharm Sci. 2013;50:623-37. https://doi.org/10.1016/j.ejps.2013.05.005.

8. Larrañeta E, McCrudden M, Courtenay A, Donnelly R. Microneedles: A new frontier in nanomedicine delivery. Pharm Res. 2016;33:1055-73. https://doi.org/10.1007/s11095-016-1885-5.

9. PRISMA. http://www.prisma-statement.org/ (2020). Accessed 8 March 2020.

10. Wei-Ze L, Mei-Rong H, Jian-Ping Z, Yong-Qiang Z, Bao-Hua $\mathrm{H}$, Ting L, et al. Super-short solid silicon microneedles for transdermal drug delivery applications. Int $\mathrm{J}$ Pharmaceutics. 2010;389:122-9. https://doi.org/10.1016/j.ijpharm.2010.01.024.

11. Khanna P, Luongo K, Strom J, Bhansali S. Sharpening of hollow silicon microneedles to reduce skin penetration force. J Micromech Microeng. 2010;20:045011 https://doi.org/10.1088/09601317/20/4/045011.

12. Vinayakumar K, Hegde G, Nayak M, Dinesh N, Rajanna K. Fabrication and characterization of gold-coated hollow silicon microneedle array for drug delivery. Microelectron Eng. 2014;128:12-18. https://doi.org/10.1016/j.mee.2014.05.039.

13. Li J, Liu B, Zhou Y, Chen Z, Jiang L, Yuan W, et al. Fabrication of a Ti porous microneedle array by metal injection molding for transdermal drug delivery. PLoS ONE. 2017;12:e0172043 https://doi.org/10.1371/journal.pone.0172043.

14. Hoang M, Ita K, Bair D. Solid microneedles for transdermal delivery of amantadine hydrochloride and pramipexole dihydrochloride. Pharmaceutics. 2015;7:379-96. https://doi.org/10. 3390/pharmaceutics7040379.

15. Olhero S, Lopes E, Ferreira J. Fabrication of ceramic microneedles - The role of specific interactions between processing additives and the surface of oxide particles in Epoxy Gel Casting. J Eur Ceram Soc. 2016;36:4131-40. https://doi.org/10.1016/j. jeurceramsoc.2016.06.035.

16. McCrudden M, Alkilani A, Courtenay A, McCrudden C, McCloskey B, Walker C, et al. Considerations in the sterile manufacture of polymeric microneedle arrays. Drug Deliv Transl Res. 2014;5:3-14. https://doi.org/10.1007/s13346-014-0211-1.

17. Lee J, Han M, Park J. Polymer microneedles for transdermal drug delivery. J Drug Target. 2012;21:211-23. https://doi.org/10. 3109/1061186x.2012.741136. 
18. Ulery B, Nair L, Laurencin C. Biomedical applications of biodegradable polymers. J Polym Sci Part B: Polym Phys. 2011;49:832-64. https://doi.org/10.1002/polb.22259.

19. Grund S, Bauer M, Fischer D. Polymers in drug delivery-state of the art and future trends. Adv Eng Mater. 2011;13:B61-87. https://doi.org/10.1002/adem.201080088.

20. Deng M, Kumbar GS, Lo W-HK, Ulery DB, Laurencin TC. Novel polymer-ceramics for bone repair and regeneration. Recent Pat Biomed Eng. 2011;4:168-84. https://doi.org/10.2174/ 1874764711104030168.

21. Tibbitt M, Rodell C, Burdick J, Anseth, K. (2015). Progress in material design for biomedical applications. Proc Natl Acad Sci USA 2015; 112: 14444-51. https://doi.org/10.1073/pnas. 1516247112.

22. Wei Q, Haag R. Universal polymer coatings and their representative biomedical applications. Mater Horiz. 2015;2:567-77. https://doi.org/10.1039/c5mh00089k.

23. Reddy N, Reddy R, Jiang Q. Crosslinking biopolymers for biomedical applications. Trends Biotechnol. 2015;33:362-9. https://doi.org/10.1016/j.tibtech.2015.03.008.

24. McAllister D, Allen M, Prausnitz M. Microfabricated microneedles for gene and drug delivery. Annu Rev Biomed Eng. 2000;2:289-313. https://doi.org/10.1146/annurev.bioeng.2.1.289.

25. Ikeno F, Lyons J, Kaneda H, Baluom M, Benet L, Rezaee M. Novel percutaneous adventitial drug delivery system for regional vascular treatment. Catheter Cardiovasc Interv. 2004;63:222-30. https://doi.org/10.1002/ccd.20167.

26. Birchall J, Clemo R, Anstey A, John D. Microneedles in clinical practice-an exploratory study into the opinions of healthcare professionals and the public. Pharm Res. 2010;28:95-106. https://doi.org/10.1007/s11095-010-0101-2.

27. Donnelly R, Garland M, Morrow D, Migalska K, Singh T, Majithiya $R$, et al. Optical coherence tomography is a valuable tool in the study of the effects of microneedle geometry on skin penetration characteristics and in-skin dissolution. J Controlled Release. 2010;147:333-41. https://doi.org/10.1016/j.jconrel.2010.08.008.

28. Bariya S, Gohel M, Mehta T, Sharma O. Microneedles: an emerging transdermal drug delivery system. J Pharm Pharmacol. 2011;64:11-29. https://doi.org/10.1111/j.2042-7158.2011.01369.x.

29. Gill H, Denson D, Burris B, Prausnitz M. Effect of microneedle design on pain in human volunteers. Clin J Pain. 2008;24:585-94. https://doi.org/10.1097/ajp.0b013e31816778f9.

30. Zahn J, Talbot N, Liepmann D, Pisano A. Journal search results Cite this for me. Biomed Microdevices. 2000;2:295-303. https://doi.org/10.1023/a:1009907306184.

31. Donnelly R, Majithiya R, Singh T, Morrow D, Garland M, Demir Y, et al. Design, optimization, and characterisation of polymeric microneedle arrays prepared by a novel laser-based micromoulding technique. Pharm Res. 2010;28:41-57. https://doi.org/10.1007/s11095-010-0169-8.

32. Demir Y, Akan Z, Kerimoglu O. Characterization of polymeric microneedle arrays for transdermal drug delivery. PLoS ONE. 2013;8:e77289 https://doi.org/10.1371/journal.pone.0077289.

33. Park J, Allen M, Prausnitz M. Biodegradable polymer microneedles: fabrication, mechanics, and transdermal drug delivery. $\mathrm{J}$ Controlled Release. 2005;104:51-66. https://doi.org/10.1016/j. jconrel.2005.02.002.

34. Prausnitz M. Microneedles for transdermal drug delivery. Adv Drug Deliv Rev. 2004;56:581-7. https://doi.org/10.1016/j.addr. 2003.10.023.

35. Davis S, Landis B, Adams Z, Allen M, Prausnitz M. Insertion of microneedles into skin: measurement and prediction of insertion force and needle fracture force. J Biomech. 2004;37:1155-63. https://doi.org/10.1016/j.jbiomech.2003.12.010.

36. Gittard S, Chen B, Xu H, Ovsianikov A, Chichkov B, MonteiroRiviere N, et al. The effects of geometry on skin penetration and failure of polymer microneedles. $\mathrm{J}$ Adhes Sci Technol. 2013;27:227-43. https://doi.org/10.1080/01694243.2012.705101.

37. Nguyen, H. Safety of microneedles for transdermal drug delivery. J Pharmacovigil. 2018; 06. https://doi.org/10.4172/2329$6887.1000 \mathrm{e} 172$.

38. Gomaa Y, Morrow D, Garland M, Donnelly R, El-Khordagui L, Meidan V. Effects of microneedle length, density, insertion time, and multiple applications on human skin barrier function: Assessments by transepidermal water loss. Toxicol Vitr. 2010;24:1971-8. https://doi.org/10.1016/j.tiv.2010.08.012.

39. Pearton M, Saller V, Coulman S, Gateley C, Anstey A, Zarnitsyn $\mathrm{V}$, et al. Microneedle delivery of plasmid DNA to living human skin: Formulation coating, skin insertion, and gene expression. J Controlled Release. 2012;160:561-9. https://doi.org/10.1016/j. jconrel.2012.04.005.

40. Bal S, Caussin J, Pavel S, Bouwstra J. In vivo assessment of safety of microneedle arrays in human skin. Eur J Pharm Sci. 2008;35:193-202. https://doi.org/10.1016/j.ejps.2008.06.016.

41. Roxhed N, Gasser T, Griss P, Holzapfel G, Stemme G. Penetration-enhanced ultrasharp microneedles and prediction on skin interaction for efficient transdermal drug delivery. J Microelectromechanical Syst. 2007;16:1429-40. https://doi.org/ 10.1109/jmems.2007.907461.

42. Larrañeta E, Moore J, Vicente-Pérez E, González-Vázquez P, Lutton R, Woolfson A, et al. A proposed model membrane and test method for microneedle insertion studies. Int J Pharmaceutics. 2014;472:65-73. https://doi.org/10.1016/j.ijpharm.2014.05.042.

43. Huh I, Kim S, Yang H, Jang M, Kang G, Jung H. Effects of two droplet-based dissolving microneedle manufacturing methods on the activity of encapsulated epidermal growth factor and ascorbic acid. Eur J Pharm Sci. 2018;114:285-92. https://doi.org/10. 1016/j.ejps.2017.12.025.

44. Liu S, Wu D, Quan Y, Kamiyama F, Kusamori K, Katsumi H, et al. Improvement of transdermal delivery of exendin-4 using novel tip-loaded microneedle arrays fabricated from hyaluronic acid. Mol Pharmaceutics. 2015;13:272-9. https://doi.org/10. 1021/acs.molpharmaceut.5b00765.

45. Kang G, Tu T, Kim S, Yang H, Jang M, Jo D, et al. Adenosineloaded dissolving microneedle patches to improve skin wrinkles, dermal density, elasticity, and hydration. Int J Cosmet Sci. 2018;40:199-206. https://doi.org/10.1111/ics.12453.

46. Medhi P, Olatunji O, Nayak A, Uppuluri C, Olsson R, Nalluri B, et al. Lidocaine-loaded fish scale-nanocellulose biopolymer composite microneedles. AAPS Pharmscitech. 2017;18:1488-94. https://doi.org/10.1208/s12249-017-0758-5.

47. Park Y, Kim B. Skin permeability of compounds loaded within dissolving microneedles dependent on composition of sodium hyaluronate and carboxymethyl cellulose. Korean J Chem Eng. 2016;34:133-8. https://doi.org/10.1007/s11814-016-0240-1.

48. Chang H, Zheng M, Yu X, Than A, Seeni R, Kang R, et al. A swellable microneedle patch to rapidly extract skin interstitial fluid for timely metabolic analysis. Adv Mater. 2017;29:1702243 https://doi.org/10.1002/adma.201702243.

49. Park Y, Ha S, Choi I, Kim K, Park J, Choi N, et al. Fabrication of degradable carboxymethyl cellulose (CMC) microneedle with laser writing and replica molding process for enhancement of transdermal drug delivery. Biotechnol Bioprocess Eng. 2016;21:110-8. https://doi.org/10.1007/s12257-015-0634-7.

50. Lee I, Lin W, Shu J, Tsai S, Chen C, Tsai M. Formulation of two-layer dissolving polymeric microneedle patches for insulin transdermal delivery in diabetic mice. J Biomed Mater Res Part A. 2016;105:84-93. https://doi.org/10.1002/jbm.a.35869.

51. Shelke N, James R, Laurencin C, Kumbar S. Polysaccharide biomaterials for drug delivery and regenerative engineering. Polym Adv Technol. 2014;25:448-60. https://doi.org/10.1002/pat.3266. 
52. Markovsky E, Baabur-Cohen H, Eldar-Boock A, Omer L, Tiram G, Ferber S, et al. Administration, distribution, metabolism, and elimination of polymer therapeutics. J Controlled Release. 2012;161:446-60. https://doi.org/10.1016/j.jconrel.2011.12.021.

53. Mansour H, Sohn M, Al-Ghananeem A, DeLuca P. Materials for pharmaceutical dosage forms: molecular pharmaceutics and controlled release drug delivery aspects. Int J Mol Sci. 2010;11:3298-322. https://doi.org/10.3390/ijms11093298.

54. Wang M, Hu L, Xu C. Recent advances in the design of polymeric microneedles for transdermal drug delivery and biosensing. Lab A Chip. 2017;17:1373-87. https://doi.org/10.1039/c7lc00016b.

55. Lee J, Park J, Prausnitz M. Dissolving microneedles for transdermal drug delivery. Biomaterials. 2008;29:2113-24. https:// doi.org/10.1016/j.biomaterials.2007.12.048.

56. Quinn H, Bonham L, Hughes C, Donnelly R. Design of a dissolving microneedle platform for transdermal delivery of a fixeddose combination of cardiovascular drugs. J Pharm Sci. 2015;104:3490-500. https://doi.org/10.1002/jps.24563.

57. Fukushima K, Ise A, Morita H, Hasegawa R, Ito Y, Sugioka N, et al. Two-layered dissolving microneedles for percutaneous delivery of peptide/protein drugs in rats. Pharm Res. 2010;28:7-21. https://doi.org/10.1007/s11095-010-0097-7.

58. Tang Z, He C, Tian H, Ding J, Hsiao B, Chu B, et al. Polymeric nanostructured materials for biomedical applications. Prog Polym Sci. 2016;60:86-128. https://doi.org/10.1016/j.progpolymsci.2016. 05.005 .

59. Zhang J, Chen B, Ashfaq M, Zhang X, Guo X. Development of a BDDEcross-linked hyaluronic acid-based microneedles patch as a dermal filler for anti-aging treatment. $\mathrm{J}$ Ind Eng Chem. 2018;65:363-9. https://doi.org/10.1016/j.jiec.2018.05.007.

60. Lee K, Lee C, Jung H. Dissolving microneedles for transdermal drug administration prepared by a stepwise controlled drawing of maltose. Biomaterials. 2011;32:3134-40. https://doi.org/10. 1016/j.biomaterials.2011.01.014.

61. Martin C, Allender C, Brain K, Morrissey A, Birchall J. Lowtemperature fabrication of biodegradable sugar glass microneedles for transdermal drug delivery applications. J Controlled Release. 2012;158:93-101. https://doi.org/10.1016/j.jconrel.2011.10.024.

62. Miyano T, Tobinaga Y, Kanno T, Matsuzaki Y, Takeda H, Wakui $\mathrm{M}$, et al. Sugar micro needles as transdermic drug delivery system. Biomed Microdevices. 2005;7:185-8. https:// doi.org/10.1007/s10544-005-3024-7.

63. Nguyen H, Banga A. Fabrication, characterization, and application of sugar microneedles for transdermal drug delivery. Therapeutic Deliv. 2017;8:249-64. https://doi.org/10.4155/tde2016-0096.

64. Matsuo K, Yokota Y, Zhai Y, Quan Y, Kamiyama F, Mukai Y, et al. A low-invasive and effective transcutaneous immunization system using a novel dissolving microneedle array for soluble and particulate antigens. J Controlled Release. 2012;161:10-17. https://doi.org/10.1016/j.jconrel.2012.01.033.

65. Hong J, Ko E, Choi S, Li K, Kim A, Park J, et al. Efficacy and safety of a novel, soluble microneedle patch for the improvement of facial wrinkle. J Cosmet Dermatol. 2017;17:235-41. https:// doi.org/10.1111/jocd.12426.

66. Chen F, Yan Q, Yu Y, Wu M. BCG vaccine powder-laden and dissolvable microneedle arrays for lesion-free vaccination. J Controlled Release. 2017;255:36-44. https://doi.org/10.1016/j. jconrel.2017.03.397.

67. Wang C, Ye Y, Hochu G, Sadeghifar H, Gu Z. Enhanced cancer immunotherapy by microneedle patch-assisted delivery of antiPD1 antibody. Nano Lett. 2016;16:2334-40. https://doi.org/10. 1021/acs.nanolett.5b05030.

68. Jiang Y, Chen B, Liu Y, Zhufu Z, Yan X, Hou X, et al. Effect of collagen scaffold with adipose-derived stromal vascular fraction cells on diabetic wound healing: A study in a diabetic porcine model. Tissue Eng Regen Med. 2013;10:192-9. https://doi.org/ 10.1007/s13770-013-0001-8.

69. Dong L, Li Y, Li Z, Xu N, Liu P, Du H, et al. Au nanocagestrengthened dissolving microneedles for chemo-photothermal combined therapy of superficial skin tumors. ACS Appl Mater Interfaces. 2018;10:9247-56. https://doi.org/10.1021/acsami. 7 b18293.

70. Kim S, Lee J, Shayan F, Kim S, Huh I, Ma Y, et al. Physicochemical study of ascorbic acid 2-glucoside loaded hyaluronic acid dissolving microneedles irradiated by electron beam and gamma-ray. Carbohydr Polym. 2018;180:297-303. https://doi. org/10.1016/j.carbpol.2017.10.044.

71. Choi J, Park S, Park J. Microneedles containing cross-linked hyaluronic acid particulates for control of degradation and swelling behavior after administration into skin. J Drug Target. 2018;26:884-94. https://doi.org/10.1080/1061186x.2018.1435664.

72. Larrañeta E, Henry M, Irwin N, Trotter J, Perminova A, Donnelly R. Synthesis and characterization of hyaluronic acid hydrogels cross-linked using a solvent-free process for potential biomedical applications. Carbohydr Polym. 2018;181:1194-205. https://doi.org/10.1016/j.carbpol.2017.12.015.

73. Mönkäre J, Reza Nejadnik M, Baccouche K, Romeijn S, Jiskoot W, Bouwstra J. IgG-loaded hyaluronan-based dissolving microneedles for intradermal protein delivery. $\mathrm{J}$ Controlled Release. 2015;218:53-62. https://doi.org/10.1016/j.jconrel.2015.10.002.

74. Liu S, Jin M, Quan Y, Kamiyama F, Katsumi H, Sakane T, et al. The development and characteristics of novel microneedle arrays fabricated from hyaluronic acid, and their application in the transdermal delivery of insulin. J Controlled Release. 2012;161:933-41. https://doi.org/10.1016/j.jconrel.2012.05.030.

75. Natural and Synthetic Biomedical Polymers - 1st Edition. https://www.elsevier.com/books/natural-and-syntheticbiomedical-polymers/kum-bar/978-0-12-396983-5 Accessed 10 April 2020.

76. Ito Y, Murano H, Hamasaki N, Fukushima K, Takada K. Incidence of low bioavailability of leuprolide acetate after percutaneous administration to rats by dissolving microneedles. Int $\mathrm{J}$ Pharm. 2011;407:126-31. https://doi.org/10.1016/j.ijpharm.2011.01.039.

77. Bayarri S, González-Tomás L, Costell E. Viscoelastic properties of aqueous and milk systems with carboxymethyl cellulose. Food Hydrocoll. 2009;23:441-50. https://doi.org/10.1016/j.foodhyd. 2008.02.002.

78. Dhar N, Akhlaghi S, Tam K. Biodegradable and biocompatible polyampholyte microgels derived from chitosan, carboxymethyl cellulose, and modified methylcellulose. Carbohydr Polym. 2012;87:101-9. https://doi.org/10.1016/j. carbpol.2011.07.022.

79. Kim J, Han M, Kim Y, Shin S, Nam S, Park J. Tip-loaded dissolving microneedles for transdermal delivery of donepezil hydrochloride for treatment of Alzheimer's disease. Eur J Pharm Biopharm. 2016;105:148-55. https://doi.org/10.1016/j.ejpb.2016. 06.006.

80. Zaric M, Becker P, Hervouet C, Kalcheva P, Ibarzo Yus B, Cocita C, et al. Long-lived tissue-resident HIV-1 specific memory $\mathrm{CD} 8+\mathrm{T}$ cells are generated by skin immunization with live virus vectored microneedle arrays. $\mathrm{J}$ Control Release. 2017;268:166-75. https://doi.org/10.1016/j.jconrel.2017.10.026.

81. Fakhraei Lahiji S, Seo S, Kim S, Dangol M, Shim J, Li C, et al. Transcutaneous implantation of valproic acid-encapsulated dissolving microneedles induces hair regrowth. Biomaterials. 2018;167:69-79. https://doi.org/10.1016/j.biomaterials.2018. 03.019.

82. Chen M, Ling M, Lai K, Pramudityo E. Chitosan microneedle patches for sustained transdermal delivery of macromolecules. Biomacromolecules. 2012;13:4022-31. https://doi.org/10.1021/ bm301293d. 
83. Jin J, Reese V, Coler R, Carter D, Rolandi M. Chitin microneedles for an easy-to-use tuberculosis skin test. Adv Healthc Mater. 2013;3:349-53. https://doi.org/10.1002/adhm.201300185.

84. Justin R, Román S, Chen D, Tao K, Geng X, Grant R, et al. Biodegradable and conductive chitosan-graphene quantum dot nanocomposite microneedles for delivery of both small and large molecular weight therapeutics. RSC Adv. 2015;5:51934-46. https://doi.org/10.1039/c5ra04340a.

85. Wu Q, Lin D, Yao S. Design of chitosan and its water soluble derivatives-based drug carriers with polyelectrolyte complexes. Mar Drugs. 2014;12:6236-53. https://doi.org/10.3390/md12126236.

86. Bellich B, D'Agostino I, Semeraro S, Gamini A, Cesàro A. "The Good, the Bad and the Ugly" of Chitosans. Mar Drugs. 2016;14:99 https://doi.org/10.3390/md14050099.

87. Rodrigues A, Emeje M. Recent applications of starch derivatives in nano-drug delivery. Carbohydr Polym. 2012;87:987-94. https://doi.org/10.1016/j.carbpol.2011.09.044.

88. Ivanova T, Lilichenko N, Zicans J, Maksimov R. Starch-based biodegradable nanocomposites: structure and properties. Solid State Phenom. 2009;151:150-3. https://doi.org/10.4028/www. scientific.net/ssp.151.150.

89. Ling M, Chen M. Dissolving polymer microneedle patches for rapid and efficient transdermal delivery of insulin to diabetic rats. Acta Biomaterialia. 2013;9:8952-61. https://doi.org/10.1016/j. actbio.2013.06.029.

90. Vora L, Courtenay A, Tekko I, Larrañeta E, Donnelly R. Pullulan-based dissolving microneedle arrays for enhanced transdermal delivery of small and large biomolecules. Int J Biol Macromolecules. 2020;146:290-8. https://doi.org/10.1016/j. ijbiomac.2019.12.184.

91. ClinicalTrials.gov. https://clinicaltrials.gov/ (2020). Accessed 27 April 2020.

92. Bentham Science Publishers Patent selections. Recent Pat Cardiovasc Drug Discov. 2010;5:82-85. https://doi.org/10.2174/ 157489010790192665.

93. ICH Official web site: ICH. https://www.ich.org/page/qualityguidelines (2020). Accessed 15 April 2020.

94. Chen B, Ashfaq M, Zhu D, Zhang X, Guo X. Controlled delivery of insulin using rapidly separating microneedles fabricated from genipin-crosslinked gelatin. Macromol Rapid Commun. 2018;39:1800075 https://doi.org/10.1002/marc.201800075.

95. Larrañeta E, Lutton R, Woolfson A, Donnelly R. Microneedle arrays as transdermal and intradermal drug delivery systems: Materials science, manufacture, and commercial development. Mater Sci Eng R Rep. 2016;104:1-32. https://doi.org/10.1016/j. mser.2016.03.001.

96. Gupta J, Gill H, Andrews S, Prausnitz M. Kinetics of skin resealing after insertion of microneedles in human subjects. $\mathrm{J}$ Control Release. 2011;154:148-55. https://doi.org/10.1016/j. jconrel.2011.05.021.

97. Martin A, McConville A, Anderson A, McLister A, Davis J. Microneedle manufacture: assessing hazards and control measures. Safety. 2017;3:25 https://doi.org/10.3390/safety3040025.

98. Microneedle drug delivery - PubMed - NCBI. https://www.ncbi. nlm.nih.gov/pubmed/?term $=$ microneedle + drug + delivery (2020). Accessed 19 March 2020.

99. Van der Maaden K, Sekerdag E, Jiskoot W, Bouwstra J. Impactinsertion applicator improves reliability of skin penetration by solid microneedle arrays. AAPS J. 2014;16:681-4. https://doi. org/10.1208/s12248-014-9606-7.

100. Chen Y, Chen B, Wang Q, Jin X, Guo X. Fabrication of coated polymer microneedles for transdermal drug delivery. J Control Release. 2017;265:14-21. https://doi.org/10.1016/j.jconrel.2017. 03.383 .

101. Donnelly R, Singh T, Woolfson A. Microneedle-based drug delivery systems: Microfabrication, drug delivery, and safety.
Drug Deliv. 2010;17:187-207. https://doi.org/10.3109/ 10717541003667798.

102. Khumpuang S, Horade M, Fujioka K, Sugiyama S. Geometrical strengthening and tip-sharpening of a microneedle array fabricated by X-ray lithography. Microsyst Technol. 2006;13:209-14. https://doi.org/10.1007/s00542-006-0173-4.

103. Patel S, Lin A, Edelhauser H, Prausnitz M. Suprachoroidal drug delivery to the back of the eye using hollow microneedles. Pharm Res. 2010;28:166-76. https://doi.org/10.1007/s11095-010-0271-y.

104. Donnelly R, Morrissey A, McCarron P, Woolfson D. Microstructured devices for transdermal drug delivery and minimallyinvasive patient monitoring. Recent Pat Drug Deliv Formul. 2007;1:195-200. https://doi.org/10.2174/187221107782331656.

105. Donnelly R, Singh T, Garland M, Migalska K, Majithiya R, McCrudden $\mathrm{C}$, et al. Hydrogel-forming microneedle arrays for enhanced transdermal drug delivery. Adv Funct Mater. 2012;22:4879-90. https://doi.org/10.1002/adfm.201200864.

106. Yan L, Raphael A, Zhu X, Wang B, Chen W, Tang T, et al. Nanocomposite-strengthened dissolving microneedles for improved transdermal delivery to human skin. Adv Healthc Mater. 2013;3:555-64. https://doi.org/10.1002/adhm.201300312.

107. Than A, Liang K, Xu S, Sun L, Duan H, Xi F, et al. Transdermal delivery of anti-obesity compounds to subcutaneous adipose tissue with polymeric microneedle patches. Small Methods. 2017;1:1700269 https://doi.org/10.1002/smtd.201700269.

108. Kim J, Kim M, Yang H, Lee K, Jung H. Droplet-born air blowing: Novel dissolving microneedle fabrication. J Control Release. 2013;170:430-6. https://doi.org/10.1016/j.jconrel.2013. 05.026.

109. Hiraishi Y, Nakagawa T, Quan Y, Kamiyama F, Hirobe S, Okada N, et al. Performance and characteristics evaluation of a sodium hyaluronate-based microneedle patch for a transcutaneous drug delivery system. Int J Pharm. 2013;441:570-9. https://doi.org/10.1016/j.ijpharm.2012.10.042.

110. Zhu Z, Ye X, Ku Z, Liu Q, Shen C, Luo H, et al. Transcutaneous immunization via rapidly dissolvable microneedles protects against hand-foot-and-mouth disease caused by enterovirus 71 . J Control Release. 2016;243:291-302. https://doi.org/10.1016/j. jconrel.2016.10.019.

111. Justin R, Chen B. Multifunctional chitosan-magnetic graphene quantum dot nanocomposites for the release of therapeutics from detachable and non-detachable biodegradable microneedle arrays. Interface Focus. 2018;8:20170055 https://doi.org/10. 1098/rsfs.2017.0055.

112. Liu S, Jin M, Quan Y, Kamiyama F, Kusamori K, Katsumi H, et al. Transdermal delivery of relatively high molecular weight drugs using novel self-dissolving microneedle arrays fabricated from hyaluronic acid and their characteristics and safety after application to the skin. Eur J Pharm Biopharm. 2014;86:267-76. https://doi.org/10.1016/j.ejpb.2013.10.001.

113. Park S, Lee H, Lee Y, Kim G, Park E, Han S, et al. Wound healing potential of antibacterial microneedles loaded with green tea extracts. Mater Sci Eng C. 2014;42:757-62. https://doi.org/ 10.1016/j.msec.2014.06.021.

114. Park Y, Kim K, Chung M, Sung J, Kim B. Fabrication and characterization of dissolving microneedle arrays for improving skin permeability of cosmetic ingredients. J Ind Eng Chem. 2016;39:121-6. https://doi.org/10.1016/j.jiec.2016.05.022.

115. Yang H, Kim S, Kang G, Lahiji S, Jang M, Kim Y, et al. Centrifugal lithography: Centrifugal lithography: Self-shaping of polymer microstructures encapsulating biopharmaceutics by centrifuging polymer drops (Adv. Healthcare Mater. 19/2017). Adv Healthc Materi. 2017; 6. https://doi.org/10.1002/adhm. 201770098.

116. Kim J, Shin J, Kim S, Noh J, Kim H, Lee J, et al. Successful transdermal allergen delivery and allergen-specific 
immunotherapy using biodegradable microneedle patches. Biomaterials. 2018;150:38-48. https://doi.org/10.1016/j.bioma terials.2017.10.013.

117. Hao Y, Chen Y, Lei M, Zhang T, Cao Y, Peng J, et al. Nearinfrared responsive PEGylated gold nanorod and doxorubicin loaded dissolvable hyaluronic acid microneedles for human epidermoid cancer therapy (Adv. Therapy. 2/2018). Adv Ther. 2018;1:1870004 https://doi.org/10.1002/adtp.201870004.

118. Choi Y, Lee S, Jeong J, Lee K, Jeong K, Yang H. et al. Nanostructured lipid carrier-loaded hyaluronic acid microneedles for controlled dermal delivery of a lipophilic molecule. Int $\mathbf{J}$ Nanomedicine. 2013; 289. https://doi.org/10.2147/ijn.s54529.

119. Yu W, Jiang G, Zhang Y, Liu D, Xu B, Zhou J. Polymer microneedles fabricated from alginate and hyaluronate for transdermal delivery of insulin. Mater Sci Eng C. 2017;80:187-96. https://doi.org/10.1016/j.msec.2017.05.143.

120. Gui Z, Wu X, Wang S, Cao Y, Wan J, Shan Q, et al. Dissolving microneedles integrated with liquid crystals facilitate transdermal delivery of sinomenine hydrochloride. J Pharm Sci. 2017;106:3548-55. https://doi.org/10.1016/j.xphs.2017.07.027.

121. Ito $\mathrm{Y}$, Kobuchi S, Inoue G, Kakumu E, Aoki M, Sakaeda T, et al. Dissolving microneedles for enhanced local delivery of capsaicin to rat skin tissue. J Drug Target. 2016;25:420-4. https://doi.org/ 10.1080/1061186x.2016.1266650.

122. Ito Y, Yamazaki T, Sugioka N, Takada K. Self-dissolving micropile array tips for percutaneous administration of insulin. J Mater Sci Mater Med. 2009;21:835-41. https://doi.org/10.1007/ s10856-009-3923-x.

123. Korkmaz E, Friedrich E, Ramadan M, Erdos G, Mathers A, Ozdoganlar O, et al. Tip-loaded dissolvable microneedle arrays effectively deliver polymer-conjugated antibody inhibitors of tumor-necrosis-factor-alpha into human skin. J Pharm Sci. 2016;105:3453-7. https://doi.org/10.1016/j.xphs.2016.07.008.

124. Chen H, Lin D, Liu F, Zhou L, Liu D, Lin Z, et al. Transdermal delivery of living and biofunctional probiotics through dissolvable microneedle patches. ACS Appl Bio Mater. 2018;1:374-81. https://doi.org/10.1021/acsabm.8b00102.

125. He M, Yang G, Zhang S, Zhao X, Gao Y. Dissolving microneedles loaded with etonogestrel microcrystal particles for intradermal sustained delivery. J Pharm Sci. 2018;107:1037-45. https://doi.org/10.1016/j.xphs.2017.11.013.

126. Zhan H, Ma F, Huang Y, Zhang J, Jiang X, Qian Y. Application of composite dissolving microneedles with high drug loading ratio for rapid local anesthesia. Eur $\mathbf{J}$ Pharm Sci. 2018;121:330-7. https://doi.org/10.1016/j.ejps.2018.06.014.

127. Chen M, Lai K, Ling M, Lin C. Enhancing immunogenicity of antigens through sustained intradermal delivery using chitosan microneedles with a patch-dissolvable design. Acta Biomater. 2018;65:66-75. https://doi.org/10.1016/j.actbio.2017.11.004.

128. Yao G, Quan G, Lin S, Peng T, Wang Q, Ran H, et al. Novel dissolving microneedles for enhanced transdermal delivery of levonorgestrel: In vitro and in vivo characterization. Int J Pharm. 2017;534:378-86. https://doi.org/10.1016/j.ijpharm.2017.10.035.

129. Poirier D, Renaud F, Dewar V, Strodiot L, Wauters F, Janimak $\mathrm{J}$, et al. Hepatitis B surface antigen incorporated in dissolvable microneedle array patch is antigenic and thermostable. Biomaterials. 2017;145:256-65. https://doi.org/10.1016/j.bioma terials.2017.08.038.

130. Ito Y, Matsumoto K, Osakama N, Yoshioka R, Kobuchi S, Sakaeda $\mathrm{T}$, et al. Dissolving microneedles as skin allergy test device. Biol Pharm Bull. 2017;40:531-4. https://doi.org/10. 1248/bpb.b16-00768. 